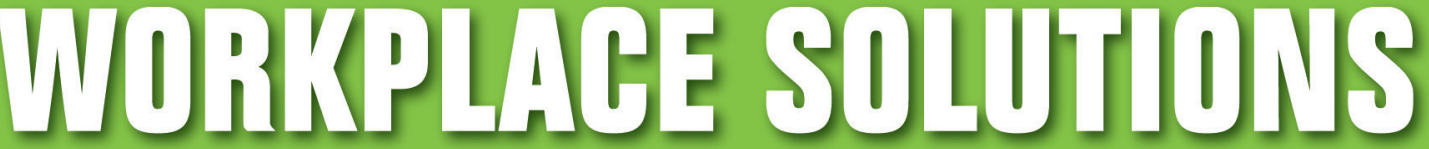

\section{Reducing Hazardous Dust Exposure When Cutting Fiber-Cement Siding}

\section{Summary}

Construction workers may be exposed to hazardous dust containing silica when cutting fiber-cement siding. The National Institute for Occupational Safety and Health (NIOSH) found that workers' exposures could be reduced by attaching a regular shop vacuum to a dust-collecting circular saw providing a simple low-cost solution.

\section{Description of Exposure}

Breathing dust that contains respirable crystalline silica can lead to silicosis, a deadly lung disease. Respirable dust is that fraction of the aerosol that is small enough to reach the deeper, gas-exchange regions of the lungs. No effective treatment exists for silicosis, but it can be prevented by controlling workers' exposures to dust containing crystalline silica. Exposure to crystalline silica has also been linked to lung cancer, kidney disease, reduced lung function, and other disorders [NIOSH 2002]. Crystalline silica is found in several construction materials, such as brick, block, fiber-cement siding, mortar and concrete. Many construction tasks have been associated with overexposure to dust containing crystalline silica [Chisholm 1999, Flanagan et al. 2003, Rappaport et al. 2003, Qi et al. 2013a]. Among these tasks are tuckpointing, concrete cutting, concrete grinding, abrasive blasting, and cutting fiber-cement siding.

The use of fiber-cement siding in construction and renovation is undergoing rapid growth. From 1991 to 2010, the market share of fiber-cement siding has climbed from $1 \%$ to $13 \%$ [U.S. Census Bureau 2013]. In contrast, the market share of wood siding in residential construction has decreased from $38 \%$ to $8 \%$ [U.S. Census Bureau 2013]. The durability and appearance of fiber-cement siding, which simulates wood without its maintenance issues, is appealing and provides a competitive advantage over other building materials. The number of workers exposed to dust containing crystalline silica will likely increase as the use of fiber-cement siding displaces other siding products [Bousquin 2009].

Fiber-cement board is cut using three methods: (1) scoring and snapping the board, (2) cutting the board using shears, and (3) cutting the board using a power saw. Although the first two methods are relatively dust-free, they are not appropriate for use with siding mainly because they are slow and not very precise [Bosuquin 2009].

Fiber-cement products can contain as much as $50 \%$ crystalline silica and cutting this material with a power saw has been shown to cause excessive exposures to respirable crystalline silica. One study by Lofgren et al. [2004] reported that cutters' uncontrolled exposures to respirable crystalline silica ranged between 0.02 to 0.17 milligram per cubic meter $\left(\mathrm{mg} / \mathrm{m}^{3}\right)$, which was up to 3.4 times the NIOSH recommended exposure limit (REL) for respirable crystalline silica of $0.05 \mathrm{mg} / \mathrm{m}^{3}$. In an in-depth field survey, Qi et al. [2013a] reported that a cutter's uncontrolled exposure to respirable crystalline silica resulted in an exposure of between 0.02 to $0.13 \mathrm{mg} / \mathrm{m}^{3}$, which was up to 2.6 times the NIOSH REL.

\section{NIOSH Study}

Power saws, such as circular saws and compound miter saws, are used to cut fiber-cement siding. These saws are normally used with 4-8 tooth polycrystalline diamond-tipped (PCD) blades specifically designed to cut fiber-cement siding and minimize dust generation. Several commercially available circular saws have dust-collecting 
features such as hoods and exhaust take-offs that can be connected to vacuum cleaners or dust-collection bags. These hoods are designed to partially enclose the saw blade.

NIOSH scientists conducted a study to develop practical engineering control recommendations for respirable crystalline silica from cutting fiber-cement siding. The first phase of the study to characterize the dust generated from cutting fiber-cement siding was conducted in a laboratory setting [Qi et al. 2014d]. The three dust-collecting circular saws evaluated in this study featured built-in dust collection containers or shrouds that functioned as a hood and partially enclosed the saw blade. When fiber-cement siding was cut, the air flow induced by the spinning blade caused a large portion of the dust generated to be collected in the container or shroud and also directed the dust to an exhaust port, which was connected to an external vacuum cleaner. The study found that the dust removal efficiency for the circular saws when used in conjunction with the external vacuum cleaner, which had a cyclone pre-separator and a high-efficiency particulate air (HEPA) filter cartridge, was greater than $81 \%$ even at a low air flow rate of 0.83 cubic meters per minute $\left(\mathrm{m}^{3} / \mathrm{min}\right)$ or 29 cubic feet per minute (CFM). It was also found that further increasing the flow rate provided by the external vacuum cleaner did not substantially improve the dust removal efficiency. A regular shop vacuum typically has a flow rate higher than $30 \mathrm{CFM}$. Thus, the results from the laboratory evaluation suggested that connecting a dustcollecting circular saw to a regular shop vacuum can be a simple and low-cost engineering solution to control the dust generated from cutting fiber-cement siding.

To further validate the effectiveness of the control, four field surveys [Qi et al. 2013b, Qi et al. 2014a, Qi et al. 2014b, Qi et al. 2014c] were conducted at locations where fibercement siding was being cut. A regular shop vacuum, which had a high efficiency disposable filter bag as a pre-filter and a cartridge filter (not HEPA), was used in these surveys. The survey results showed that the 10-hour time weighted average (TWA) exposure to respirable crystalline silica for the workers who mainly cut fiber-cement siding on the job sites was controlled to well below the NIOSH REL. These findings indicated that the engineering control measure evaluated, if used properly, was effective in reducing worker exposures to concentrations below the NIOSH REL for respirable crystalline silica. This engineering control measure has the potential to provide an effective, simple and low cost (comparing to HEPA vacuums) solution for workers cutting fiber-cement siding.

\section{Recommended Controls}

\section{LEV System}

- Use a shop vacuum with an air-flow rate of about or higher than 30 CFM. A vacuum hose can be used to attach the circular saw to the shop vacuum. Figures 1 and 2 depict the circular saw with dust collector and how it was connected to the shop vacuum during the NIOSH field evaluation.

- The hose that connects the shop vacuum to the saw should be of sufficient size (1.25-inch or greater inner diameter) to allow adequate airflow for the capture and transport of saw dust. To maximize efficiency, the hose should only be as long as necessary and be kept as straight as possible.

- A high efficiency disposable filter bag can be used as a prefilter in the shop vacuum to capture most of the dust. This will prolong the life of the filter cartridge that captures the dust that goes through the filter bag.

- The shop vacuum and the circular saw can be plugged into an intelligent vacuum switch. This eliminates the distraction for the operator of turning on and off a dust collection system and ensures the vacuum is running while operating the saw, avoiding uncontrolled dust release. The switch also allows for delay in turning off the shop vacuum when the saw is turned off, removing the remaining dust in the vacuum hose following the cutting of a board. Some shop vacuums have incorporated such an intelligent vacuum switch. For those shop vacuums that don't have it, an aftermarket device with the same feature can be purchased and utilized [Qi et al. 2013b, Qi et al. 2014a, Qi et al. 2014b, Qi et al. 2014c].

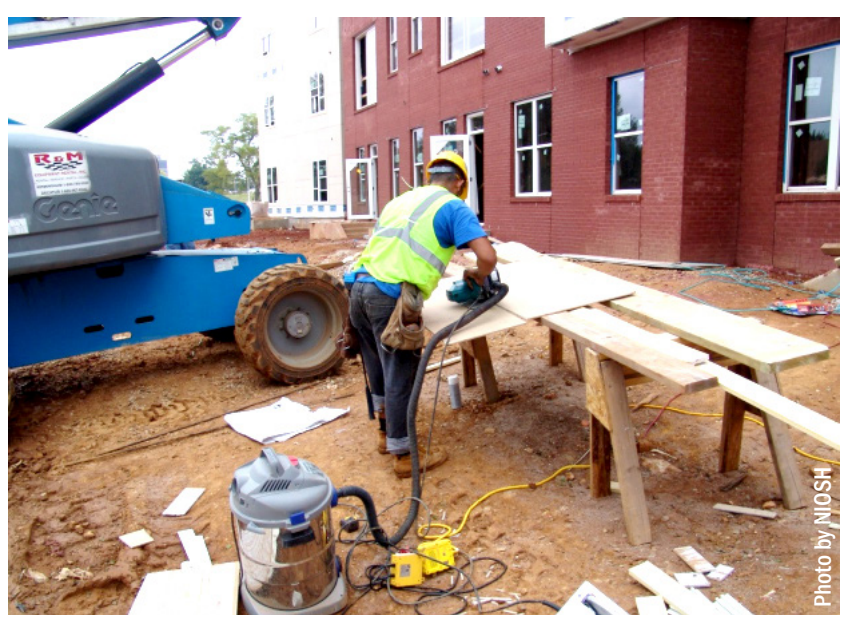

Figure 1. Rear view of a worker bent at the waist wearing a helmet while cutting fiber cement boards on trestles. He is using a dust collecting circular saw connected to a vacuum. A blue boom lift and red brick building are in the background. 


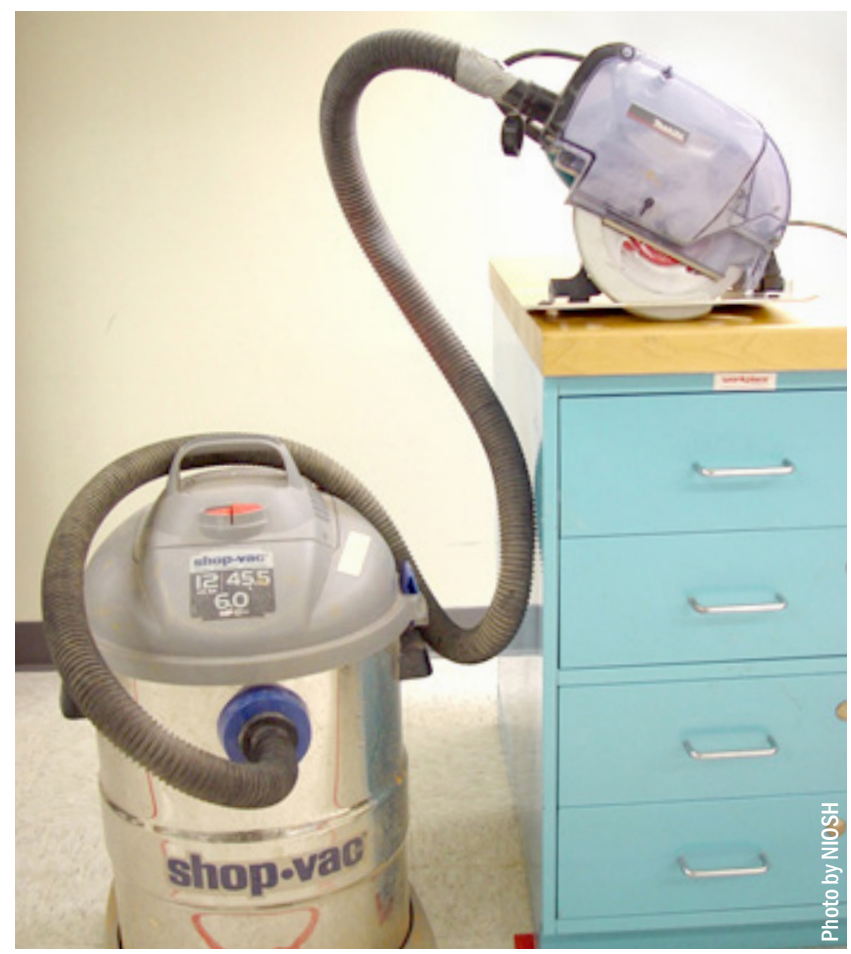

Figure 2. A dust collecting circular saw sitting on a blue filing cabinet and connected to a shop vacuum that is on the floor.

\section{Circular Saws}

- Use only circular saws with a built-in dust collection container or shroud that functions as a hood, partially encloses the saw blade, and can be easily connected to the LEV system.

\section{Circular Saw Blades}

- Use polycrystalline diamond-tipped (PCD) blades designed to be used to cut fiber-cement siding. Compared to Carbide-tipped blades, they provide a cleaner cut of the siding, exhibit a longer wear life, and may reduce the dust generated.

\section{Work Practices}

- When using a power saw (circular or miter), cut fibercement siding outdoors when practical.

- Avoid cleaning up fugitive fiber-cement dust on job site using dry sweeping, and use vacuum instead.

- Provide a covered trash can near the work station for saw operators to dispose of collected dust. Follow local, state and/or Federal regulations when disposing of fibercement dust.
- Ensure the shop vacuum is maintained according to manufacturer recommendations.

- Ensure the shop vacuum is inspected daily for defects (new filter bags and cartridges inspected for holes, cuts, etc.) and that filter bag and cartridge filter are changed regularly to prevent restricted air flow.

- Do not clean the cartridge filter, work clothing, or other areas with compressed air. In addition to creating a hazardous dust cloud, compressed air can damage the filter.

- Inspect the saw blade frequently and change as necessary to ensure the blade is not excessively worn.

- Keep nearby workers clear from any dust generating operation.

- Written procedures should be developed and employees trained on the hazards of silica exposure and the proper methods to reduce exposure.

\section{Respirators}

The dust controls provided in this document may greatly reduce worker exposure to hazardous dust; however, NIOSH recommends the use of half-facepiece particulate respirators with N95 or better filters for airborne exposures to crystalline silica at concentrations less than or equal to $0.5 \mathrm{mg} /$ $\mathrm{m}^{3}$ [NIOSH 2008]. Employers should consult with an occupational safety and health professional and/or certified industrial hygienist to determine the respirator that would be best suited for the application. Employers should always follow the Occupational Safety and Health Administration (OSHA) Respiratory Protection Standard (29 CFR 1910.134) if respiratory protection is used. (www.osha.gov/SLTC/ etools/respiratory/index.html). NIOSH guidance for selecting respirators can be found at http://www.cdc.gov/niosh/ docs/2005-100/default.html.

\section{Acknowledgments}

This document was prepared by Chaolong Qi, NIOSH Division of Applied Research and Technology, and John J. Whalen, formerly with NIOSH.

\section{References}

Bousquin J [2009]. Fiber cement's aesthetics and durability continue to gain fans. Building Products Magazine. Publication date: February 13, 2009. http://www.ebuild. com/articles/875202.hwx]

Chisholm J [1999]. Respirable dust and respirable silica concentrations from construction activities. Indoor Built Environ 8:94-106. http://www.karger.com/Article/ Abstract/24619 
Flanagan ME, Seixas N, Majar M, Camp J, Morgan M [2003]. Silica dust exposures during selected construction activities. Am Ind Hyg Assoc J 64:319-328. http://deohs. washington.edu/sites/default/files/images/general/Majar Thesid.pdf

Lofgren DJ, Johnson DC, Walley TL [2004]. OSHA Compliance issues: silica and noise exposure during installation of fiber-cement siding. Occup Environ Hyg J 1:D1-D6. http://www.tandfonline.com/doi/pdf/10.1080/154596204 90264418

NIOSH [2002]. NIOSH Hazard Review: Health effects of occupational exposure to respirable crystalline silica. DHHS (NIOSH) Publication No. 2002-129. http://www.cdc.gov/niosh/docs/2002-129/pdfs/ 2002-129.pdf

NIOSH [2008]. NIOSH Policy Statement: respiratory protection recommendations for airborne exposures to crystalline silica. By the Respirator Policy Group (BerryAnn R, Lentz TJ, Ahlers H, Barsan M, Hearl F). DHHS (NIOSH) Publication No. 2008-140. http://www.cdc.gov/niosh/ docs/2008-140/pdfs/2008-140.pdf

Qi C, Echt A, See M [2013a]. In-Depth Survey Report: partnering to control dust from fiber-cement siding. DHHS (NIOSH) Report No. EPHB 358-11a. http://www.cdc.gov/ niosh/surveyreports/pdfs/358-11a.pdf

Qi C, Hirst DVL, Echt A [2013b]. In-Depth Survey Report: : partnering to control dust from fiber-cement siding. DHHS (NIOSH) Report No. EPHB 358-12a. http://www.cdc.gov/ niosh/surveyreports/pdfs/358-12a.pdf

Qi C, Echt A [2014a]. In-Depth Survey Report: partnering to control dust from fiber-cement siding. DHHS (NIOSH) Report No. EPHB 358-13a. http://www.cdc.gov/niosh/ surveyreports/pdfs/358-13a.pdf

Qi C, Garcia A, Echt A [2014b]. In-Depth Survey Report: partnering to control dust from fiber-cement siding. DHHS (NIOSH) Report No. EPHB 358-14a. http//www.cdc.gov/ niosh/surveyreports/pdfs/358-14a.pdf

Qi C, Kratzer J, Echt A [2014c]. In-Depth Survey Report: partnering to control dust from fiber-cement siding. DHHS (NIOSH) Report No. EPHB 358-15a. http://www.cdc.gov/ niosh/surveyreports/pdfs/358-15a.pdf

Qi C, Echt A, Gressel M [2014d]. Evaluation of the dust generation and engineering control for fiber-cement siding. DHHS (NIOSH) Report No. EPHB 358-16a. http://www. cdc.gov/niosh/surveyreports/pdfs/358-16a.pdf

Rappaport SM, Goldberg M, Susi P, Herrick RF [2003]. Excessive exposure to silica in the U.S. construction industry. Ann Occup Hyg 47:111-122.

US Census Bureau [2013]. Survey of construction, principle type of exterior wall material of new one-family houses completed. http://www.census.gov/const/C25Ann/sftotalex wallmat.pdf

\section{Suggested Citation}

NIOSH [2015]. Reducing hazardous dust exposure when cutting fiber-cement siding. By Qi C, Whalen JJ. Cincinnati, OH: U.S. Department of Health and Human Services, Centers for Disease Control and Prevention, National Institute for Occupational Safety and Health. DHHS (NIOSH) Publication No. 2015-185.

\section{For More Information}

To receive documents or other information about occupational safety and health topics, contact NIOSH at

Phone: 1-800-CDC-INFO (1-800-232-4636)

TTY: 1-888-232-6348.E-mail: cdcinfo@cdc.gov

or visit the NIOSH website at www.cdc.gov/niosh.

For a monthly update on news at NIOSH, subscribe to NIOSH eNews by visiting www.cdc.gov/niosh/eNews.

Mention of any company or product does not constitute endorsement by NIOSH. In addition, citations to websites external to NIOSH do not constitute NIOSH endorsement of the sponsoring organizations or their programs or products. Furthermore, NIOSH is not responsible for the content of these websites.

\section{Reducing Hazardous Dust Exposure When Cutting Fiber-Cement Siding}

This document is in the public domain and may be freely copied or reprinted. NIOSH encourages all readers of the Workplace Solutions to make them available to all interested employers and workers.

As part of the Centers for Disease Control and Prevention, NIOSH is the Federal agency responsible for conducting research and making recommendations to prevent workrelated illnesses and injuries. All Workplace Solutions are based on research studies that show how worker exposures to hazardous agents or activities can be significantly reduced.

DHHS (NIOSH) Publication No. 2015-185 